
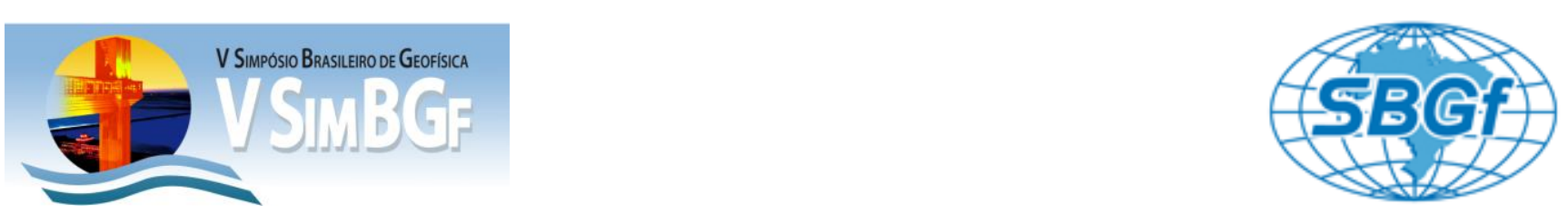

\title{
Análise do fenômeno de llha Urbana de Calor no centro comercial da cidade de Taguatinga, DF
}

*Cíntia Rocha da Trindade (cintiarochat@gmail.com - Mestranda do Programa de Geociências Aplicadas - IG/ UnB) Edson Benício de Carvalho Junior(edsonbenicio@gmail.com- Docente do Instituto de Física/ UCB) Adriana Chatack Carmelo (chatack@unb.br - Docente do Instituto de Geociências/ UnB)

Copyright 2012, SBGf - Sociedade Brasileira de Geofísica

Este texto foi preparado para a apresentação no V Simpósio Brasileiro de Geofísica, Salvador, 27 a 29 de novembro de 2012. Seu conteúdo foi revisado pelo Comitê Técnico do V SimBGf, mas não necessariamente representa a opinião da SBGf ou de seus associados. É proibida a reprodução total ou parcial deste material para propósitos comerciais sem prévia autorização da SBGf.

\section{Resumo}

Este trabalho apresenta resultados da análise de imagens termais, obtidas pelo sensor ASTER, da região de Taguatinga, Distrito Federal. O objetivo foi verificar a existência do fenômeno de ilha urbana de calor (ICU) no Centro comercial da cidade, motivado pela notória mudança na urbanização causada por ações antrópicas. Os resultados deste estudo servirão de motivação para repensar o planejamento e o desenvolvimento urbano, melhorando a qualidade de vida da população, em relação ao conforto térmico.

\section{Introdução}

O termo sensoriamento remoto é usado para definir a tecnologia que permite a aquisição de informações de algumas características de um objeto, sem que, necessariamente, se estabeleça contato físico com ele (Elachi, 1987). É uma ferramenta de grande potencial na obtenção de imagens orbitais, as quais possibilitam ter informações sobre recursos terrestres e dados meteorológicos (Florenzano, 2002). Uma das principais vantagens das técnicas de sensoriamento é a eficácia na identificação de fenômenos climáticos urbanos, como o ICU, que tende a causar desconforto térmico em locais com grandes edificações, pouca vegetação, e muita concentração de concreto e asfalto.

A cidade de Taguatinga está a oeste de Brasília (Figura 1), sua expansão territorial é de $442,9 \mathrm{Km}^{2}$ (IBGE), sendo a área urbana dividida em três setores bem definidos urbanisticamente: Norte, Sul e Central. Na região Norte há áreas residenciais, de comércio e indústria; na Sul há áreas residências, de comércio, setores hoteleiro e de concessionárias. Na região Central estão principalmente as atividades bancárias, de comércio, serviços e intensa movimentação de veículos (Vasconcelos, 1988).

Mesmo com o significativo desenvolvimento do setor urbano, é possível encontrar vegetação em locais mais antigos e nas proximidades da região, o que gera um contraste no perfil térmico da cidade. Áreas com revestimento ou impermeabilização, como asfalto e concreto, apresentam temperaturas mais elevadas em superfície.

Como o Centro comercial da cidade interliga outros setores e é bastante frequentado pela população, pode sofrer a ação de ICU.
As imagens obtidas pelo satélite TERRA (Earth Observing System - EOS), sensor ASTER, podem ser usadas para estudo e esclarecimento da distribuição de temperatura do centro comercial, em relação aos setores Norte, Sul e a área de preservação ambiental, ARIE JK, que segundo o SNUC (Lei 9.985 de 18 de julho de 2000), se enquadra na categoria de Área de Relevante Interesse Ecológico - ARIE (Figura 1).

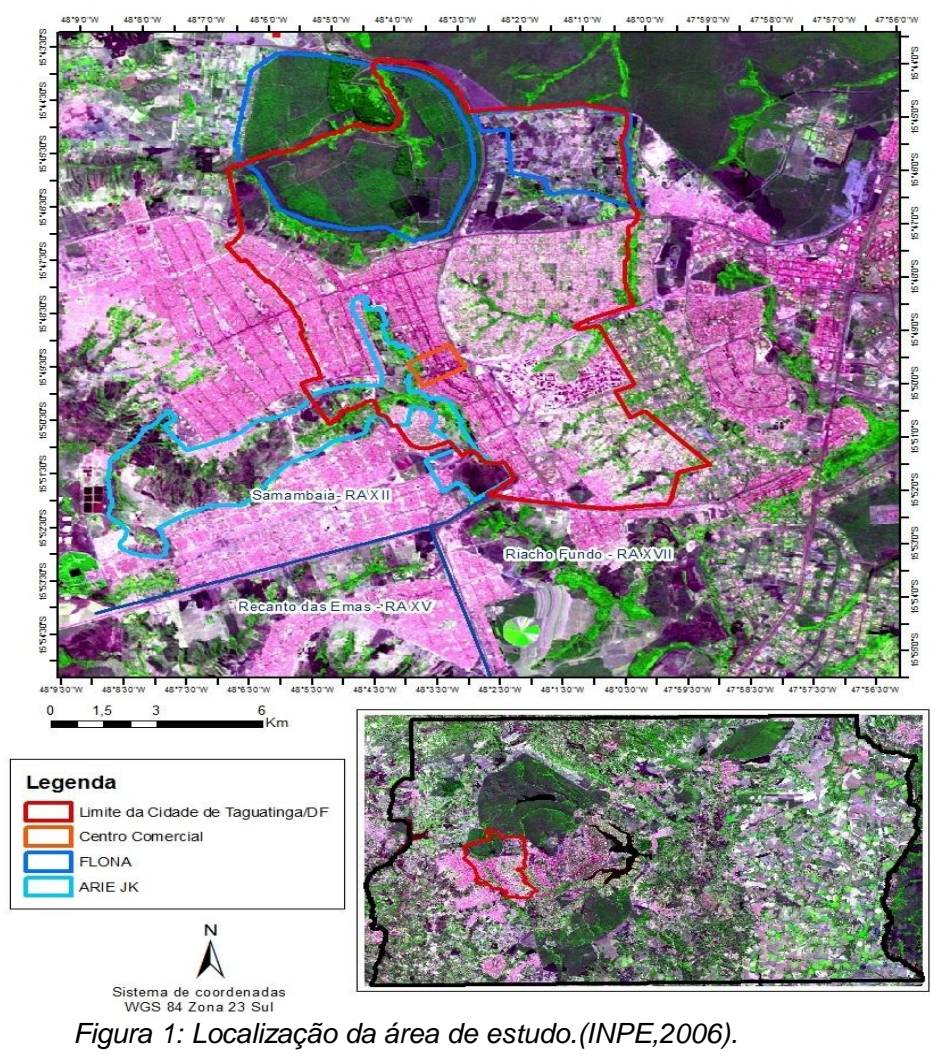

\section{Metodologia/ Problema Investigado}

\section{Sensoriamento Termal}

O método utilizado usou o sensoriamento termal onde as imagens obtidas estão no intervalo de 8 a $12 \mu \mathrm{m}$. Os corpos que estão na superfície terrestre emitem radiação eletromagnética com intensidades de emitância proporcionais a sua temperatura de superfície (Nascimento, 2001). Porém, condições climáticas interferem na obtenção da temperatura de superfície, de modo que os dados obtidos pela imagem termal variam com tais condições. Em dias ensolarados os materiais 
terão maiores temperatura de superfície (Trindade, 2010).

A aquisição das imagens do sensor ASTER (Advanced Spaceborne Thermal Emission and Reflection Radiometer) foi efetuada a partir do sítio do Serviço Geológico Americano - USGS. A escolha das imagens foi criteriosa para evitar a interferência de nuvens e muita incidência de luz solar.

O processamento dos dados foi efetuado a partir dos softwares ENVI 4.4 e ArcGIS 9.2, sendo o primeiro software utilizado para classificação da cobertura da superfície e mapeamento do campo térmico, e o último para geração dos mapas.

Para a análise de ICU, dois segmentos foram traçados, estrategicamente. Um com intuito de abranger o Centro Comercial e a ARIE JK e outro extrapolar os limites da Cidade, com o intuito de observar as diferenças de temperatura de superfície para se obter as características térmicas de áreas urbanas.

\section{Resultados}

A figura 2 apresenta 0 transector traçado no sentido sudoeste-nordeste (segmento de reta, $A B$, com cor cinza), o qual abrange o Centro Comercial e a ARIE JK.

Os pontos que apresentaram tons mais avermelhados possuem maiores temperaturas de superfície ( temperaturas de $45,1^{\circ} \mathrm{C}$ à $>49^{\circ} \mathrm{C}$ ). Na ARIE $\mathrm{JK}$, as temperaturas foram mais baixas devido à presença de vegetação (temperaturas entre $28^{\circ} \mathrm{C}$ e $39^{\circ} \mathrm{C}$ ).

A figura 3 mostra o perfil térmico na forma gráfica, o eixo y apresenta a temperatura de superfície em graus centígrados $\left({ }^{\circ} \mathrm{C}\right)$, das duas áreas analisadas, o eixo $\mathrm{x}$, a localização do pixel na imagem. A variação de temperatura entre o pico mais alto e o mais baixo foi de $17^{\circ} \mathrm{C}$, mostrando as diferenças térmicas dos dois alvos escolhidos.

O maior pico apresentado no perfil foi de $45^{\circ}$, caracterizando a região do Centro Comercial de Taguatinga.

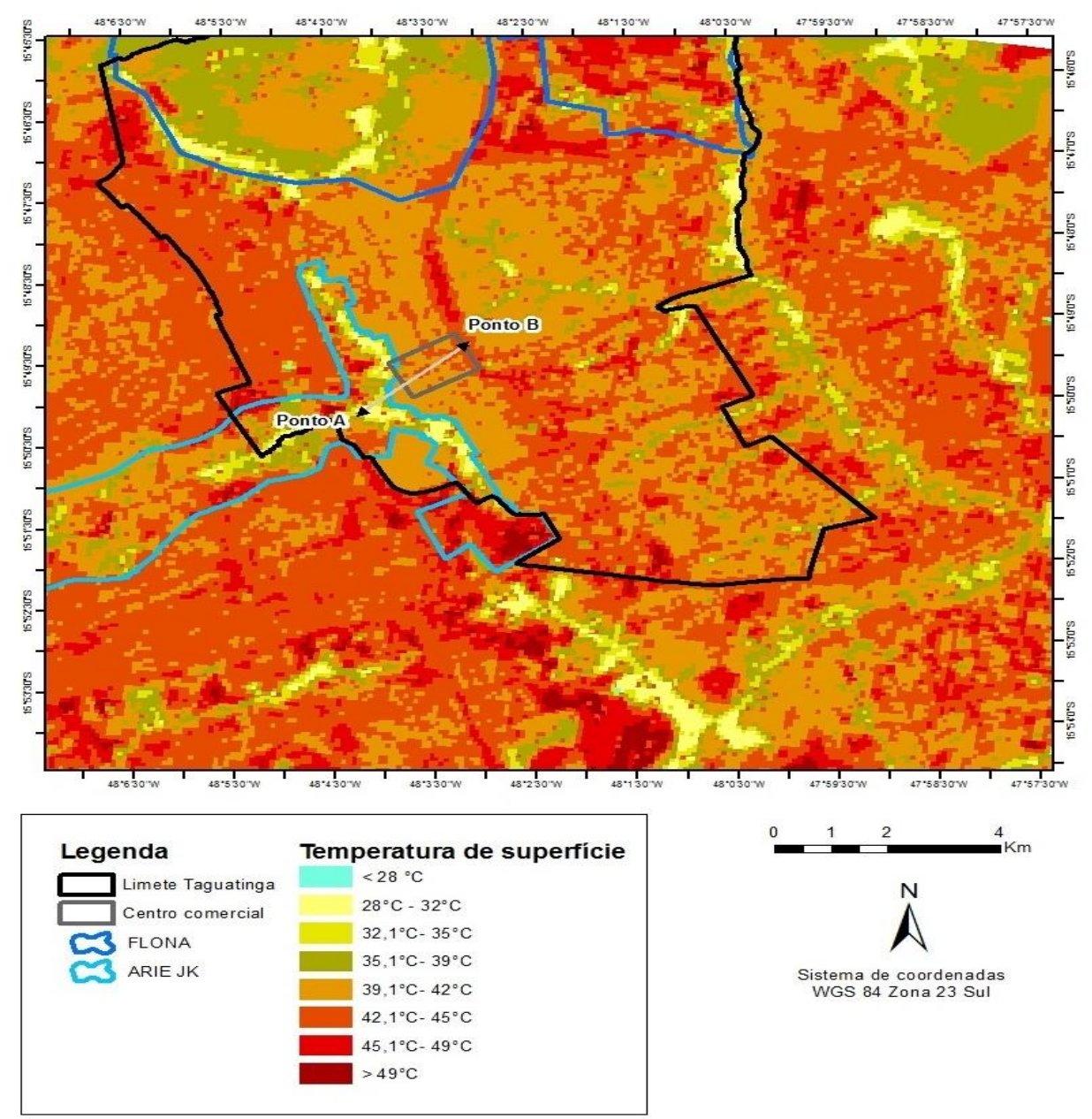

Figura 2: Composição Colorida RGB/ 141210 Taguatinga-DF. Em detalhe o segmento de reta AB, sentido sudoestenordeste (ASTER, 02/02/2006). 


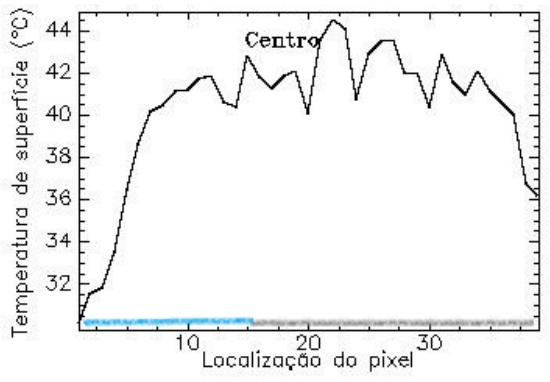

LEGENDA

Centro Comercial

ARIE JK

Figura 3: Perfil térmico correspondente ao segmento de reta $A B$ sentido sudoeste-nordeste.
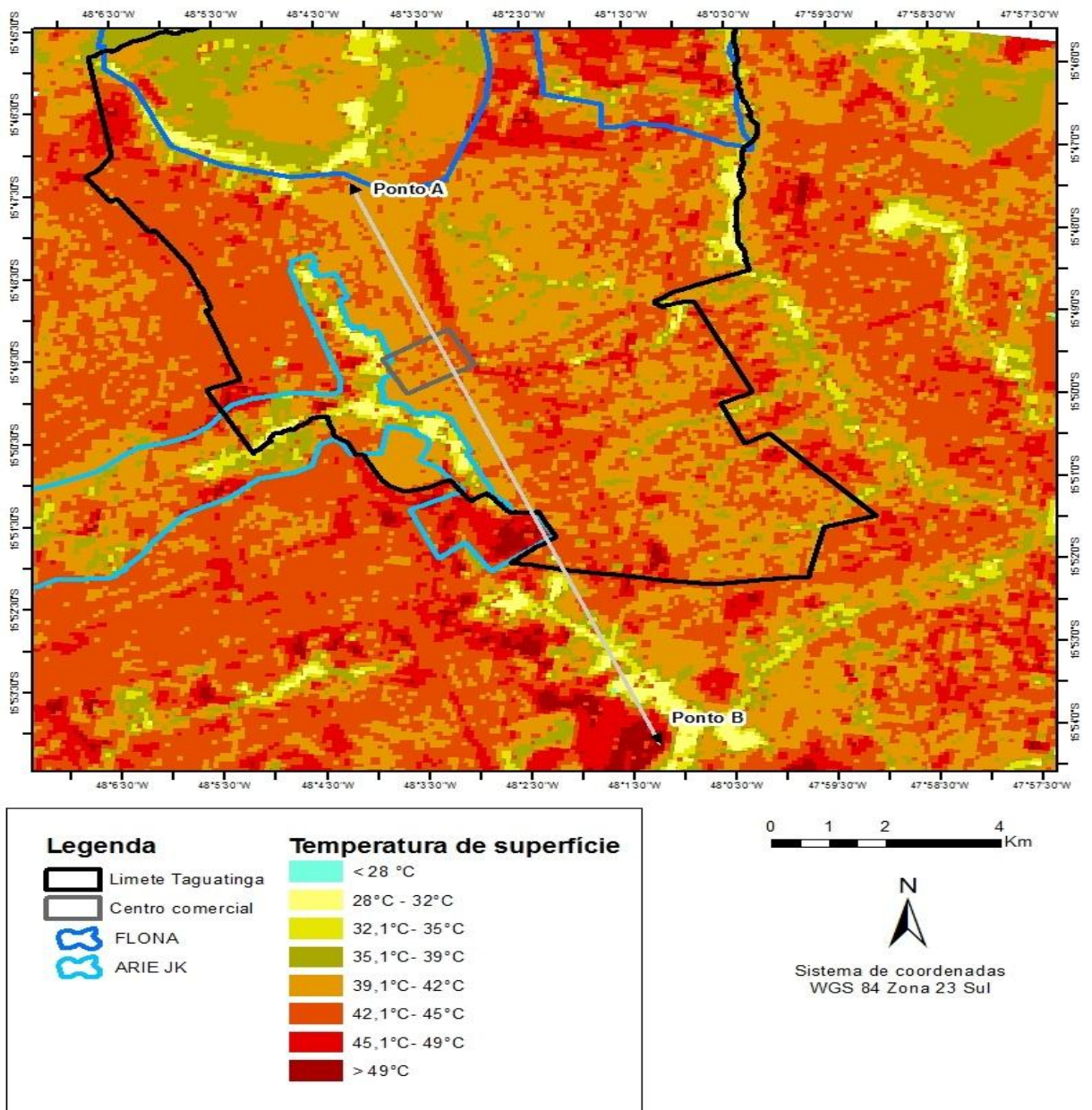

É possível observar nas imagens termal (Figura 4) e Landsat, composição colorida RGB/ 231 (Figura 1), que a Cidade de Taguatinga é fortemente urbanizada.

A figura 4 mostra 0 segundo transector traçado no sentido nordeste-sudeste (seguimento de reta, $A B$, com cor cinza), extrapolado, intencionalmente, dos limites políticos de Taguatinga. O segmento abrangeu limites da Cidade com a Floresta Nacional - FLONA e limites com a cidade do Riacho Fundo I.

O segundo perfil térmico (Figura 5), traçado na forma gráfica, representa a distribuição térmica da Cidade em seu principal eixo urbanístico, mostrando temperaturas altas $\left(39,1^{\circ} \mathrm{C}\right.$ a $\left.49^{\circ} \mathrm{C}\right)$, devido à forte urbanização.

Neste perfil, destacaram-se dois picos, um relacionado ao Centro Comercial e outro a porção sul da Cidade, áreas urbanizadas. 
Ao comparar as temperaturas das extremidades do perfil com as do Centro, percebe-se que as temperaturas do Centro são maiores, que as outras áreas estudadas. Essa diferença é devido a uma boa cobertura vegetal próximo a FLONA e na cidade do Riacho Fundo I, caracterizando temperaturas mais baixas.
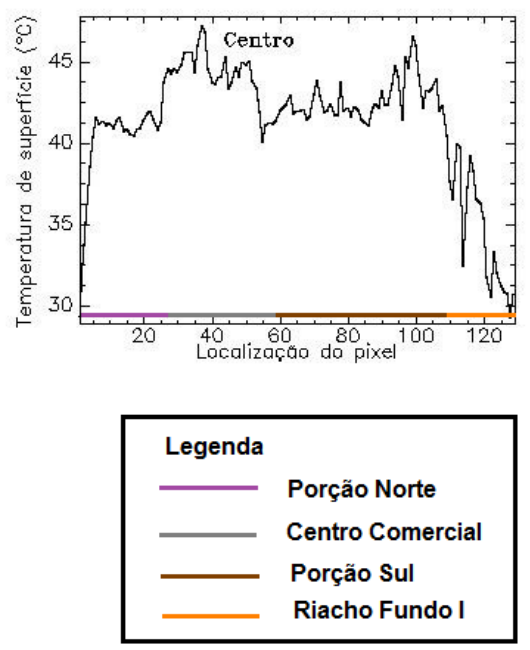

Figura 5: Perfil térmico correspondente ao segmento de reta $A B$ sentido nordeste-sudeste.

\section{Conclusões}

Para analisar a Ilha Urbana de Calor (ICU) os métodos de investigação devem levar em consideração a temperatura de superfície, a interferência de nuvens, a direção e a intensidade dos ventos. Enfatiza-se que apesar de serem elementos distintos, as temperaturas do ar e da superfície terrestre podem estar relacionadas.

O método de sensoriamento remoto, que permitiu a obtenção da informação de temperatura de superfície da cidade de Taguatinga, mostra que existe pouca vegetação e grande atividade comercial no Centro, caracterizando essa região uma ICU.

O Centro Comercial foi escolhido como objeto de estudo por interligar todos os setores da cidade e ser uma das regiões de maior fluxo comercial e com elementos físicos (construções, pavimentação e curso de veículos), os quais caracterizam uma ICU.

As informações de temperatura de superfície obtidas nas imagens termais são importantes indicadores de planos urbanísticos, realçando pólos com fortes características industriais, comerciais e áreas de preservação ambiental.

Isto pode tornar-se um elemento importante a ser utilizado em políticas públicas que visem na melhoria da saúde pública e no planejamento urbano.

\section{Agradecimentos}

Ao professor Cláusio Teza pelo auxilio na aquisição das imagens e na utilização dos softwares.

\section{Referências}

ELACHI C.1987. Introduction to physics and techniques of Remote Sensing. New York. Wiley \& Sons.

FLORENZANO TG. 2002. Imagens de satélite para estudos ambientais. Oficina de textos. São Paulo.

OKE TR. 1972. City size and the urban heat island. In: Conference on urban environment and second conference on biometeorology sponsored by the American meteorological society. Philadelphia: A.M.S, out./nov. 1972. p. 144-146.

NASCIMENTO DF, BARROS JR. 2009. Identificação de ilhas de calor por meio de sensoriamente remoto: estudo de caso no município de Goiânia- GO/2001. Boletim Goiano de Geografia, Goiânia, Brasil, jan./jun., p.119134.

TEZA CTV, BAPTISTA. 2005. Identificação do fenômeno ilhas urbanas de calor por meio de dados ASTER on demand 08 - Kinetic Temperature (III): metrópoles brasileiras. Anais XII Simpósio Brasileiro de Sensoriamento Remoto, Goiânia, Brasil, 16-21 abril, INPE, p. 3911-3918.

VASCONCELOS A. 1988. As cidades satélites de Brasília. 370. 